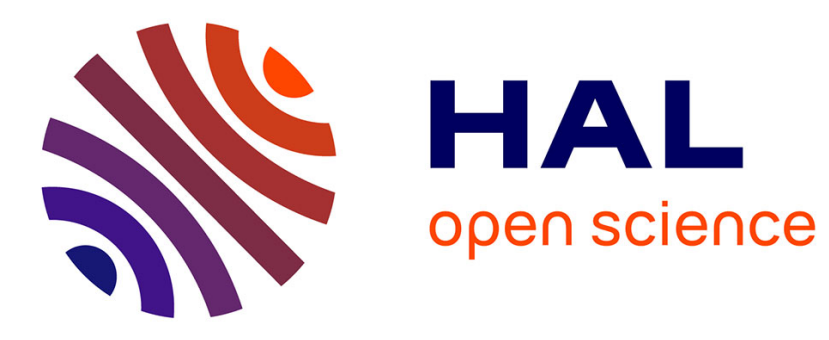

\title{
Use of photoswitchable fluorescent proteins for droplet-based microfluidic screening
}

\author{
Adilya Dagkesamanskaya, Krzysztof Langer, Alexandra Tauzin, Catherine \\ Rouzeau, Delphine Lestrade, Gabrielle Potocki-Veronese, Laurent Boitard, \\ Jérôme Bibette, Jean Baudry, Denis Pompon, et al.
}

\section{To cite this version:}

Adilya Dagkesamanskaya, Krzysztof Langer, Alexandra Tauzin, Catherine Rouzeau, Delphine Lestrade, et al.. Use of photoswitchable fluorescent proteins for droplet-based microfluidic screening. Journal of Microbiological Methods, 2018, 147, pp.59 - 65. 10.1016/j.mimet.2018.03.001 . hal01849551

\section{HAL Id: hal-01849551 \\ https://hal.science/hal-01849551}

Submitted on 5 Jun 2019

HAL is a multi-disciplinary open access archive for the deposit and dissemination of scientific research documents, whether they are published or not. The documents may come from teaching and research institutions in France or abroad, or from public or private research centers.
L'archive ouverte pluridisciplinaire HAL, est destinée au dépôt et à la diffusion de documents scientifiques de niveau recherche, publiés ou non, émanant des établissements d'enseignement et de recherche français ou étrangers, des laboratoires publics ou privés. 


\section{Use of photoswitchable Fluorescent Proteins for droplet-based microfluidic screening.}

Adilya Dagkesamanskaya*a ${ }^{*}$, Krzysztof Langer*b, Alexandra Tauzin ${ }^{\mathrm{a}}$, Catherine Rouzeau ${ }^{\mathrm{a}}$, Delphine Lestradec, Gabrielle Potocki-Veronese $^{\mathrm{a}}$, Laurent Boitard ${ }^{\mathrm{b}}$, Jérôme Bibette ${ }^{\mathrm{b}}$, Jean Baudry ${ }^{\mathrm{b}}$, Denis Pompon $^{\mathrm{a}}$ and Véronique Anton-Leberre ${ }^{\mathrm{a}}$.

*These authors contributed equally

aLISBP, Université de Toulouse, CNRS, INRA, INSA, Toulouse, France

bLaboratoire Colloïdes et Matériaux Divisés, the Institute of Chemistry, Biology and Innovation (CBI) - ESPCI ParisTech, CNRS

- UMR 8231, PSL* Research University, 10 rue Vauquelin, 75005 Paris, France

'TWB, Université de Toulouse, CNRS, INRA, INSA, Toulouse, France

\section{Abstract}

Application of droplet-based microfluidics for the screening of microbial libraries is one of the important ongoing development in functional genomics/metagenomics. In this article, we propose a new method that can be employed for the high-throughput profiling of cell growth. It consists in lightdriven labelling droplets that contain growing cells directly in microfluidics observation chamber, followed by recovery of the labelled cells. This method is based on intracellular expression of green to red switchable fluorescent proteins. The proof of concept is established here for two commonly used biological models, E.coli and S.cerevisiae. Growth of cells in droplets was monitored under a microscope and, depending on the targeted phenotype, the fluorescence of selected droplets was switched from a "green" to a "red" state. Red fluorescent cells from labelled droplets were then successfully detected, sorted with the Fluorescence Activated Cell Sorting machine and recovered. Finally, the application of this method for different kind of screenings, in particular of metagenomic libraries, is discussed and this idea is validated by the analysis of a model mini-library.

Key words: Droplet-based microfluidics; library screening; photoconvertible fluorescent protein; Saccharomyces cerevisiae; Escherichia coli; Fluorescence Activated Cell Sorting.

\section{Introduction}

Droplet-based microfluidics is an innovative and powerful approach to assess cellular properties at the cell and micro-colony level. It has been successfully applied to metagenomics in the past three years (Colin et al., 2015; Gielen et al., 2018; Najah et al., 2014). Diverse, specific features can be detected by this method using absorbance- (Gielen et al., 2016) or fluorescence-activated droplet sorting (Baret et al., 2009) as well as microscopy: enzyme activity (Hosokawa et al., 2015), growth rate (Boitard et al., 2012a), colony shape, variations of gene expression, cellular responses to different agents (antibiotics and toxic molecules), biological molecule production and secretion (Mazutis et al., 2013a) etc. This method gives the possibility to screen large numbers of individually growing cells and to reveal heterogeneity within a cell population. Applying this technique for screening requires that cells with desired features is recovered following droplet observation, in order to perform DNA sequencing or further phenotypic analysis. However, direct and on-the-spot access to a chosen droplet is not possible for the majority of systems used, since the microfluidic channels or chambers are usually well sealed in order to prevent evaporation of continuous and dispersed phases. Therefore, to manage cell recovery from any droplet of interest, cells from selected droplets have to be labelled during observation, thus allowing their subsequent sorting. One of the approaches that is used to discriminate droplets with cells producing specific target molecules (e.g., enzymes and antibodies) 
from non-producing ones is co-encapsulation with a reporter molecule such as a fluorogenic substrate (Agresti et al., 2010; Hosokawa et al., 2015; Sjostrom et al., 2014; Wang et al., 2014; Zinchenko et al., 2014) or with fluorescent microbeads allowing to capture the secreted products (Mazutis et al., 2013b). In these cases, fluorescence-based sorting can only be performed at the droplet level, since the fluorescent particles belong to the media surrounding the cells in the droplet and not to the cells themselves. Droplets recovered from the observation chamber can be sorted either by special droplet sorters developed in microfluidics specialized laboratories (Baret et al., 2009), or by easier and more available commercial fluorescence-activated cell sorting (FACS) devices (Terekhov et al., 2017; Zinchenko et al., 2014). The latter technique requires conversion of aqueous droplets of water-in-oil emulsions into a double, water-in-oil-in-water emulsion, involving additional steps in droplet preparation. For some types of screening based on contact between the droplets ("droplet shrinking" due to yeast growth, for example, described by (Boitard et al., 2012a) a aqueous layer around the droplets must be added after observation, which can lead to the loss of some positive hits. Although equipment for direct water-in-oil droplet sorting exist in several microfluidics laboratories, these instruments cannot be routinely used due to limited access to this not yet commercialized material.

Here we describe a new screening strategy that combines the simplicity of water-in-oil droplet generation with that of FACS utilization. This workflow, which allows to specifically label the droplet during microscopy-based phenotype screening and to recover the living cells after FACs sorting, is based on the use of a photoconvertible fluorescent protein (PCFP). PCFPs are fluorescent proteins whose fluorescence properties can be switched on or off, by a pulse of light of a specific wavelength. In the last ten years, many new PCFPs were described and novel applications in cell imaging have been developed, such as the study of the redistribution of a protein of interest inside a cell (Miyawaki et al., 2003), organelle labeling and tracking (Molina and Shirihai, 2009), cell labelling (Lukyanov et al., 2005), protein degradation studies (Zhang, 2007), and super-resolution microscopy based on their photoswitching properties (Chudakov et al., 2007). We propose to use switchable fluorescent proteins produced inside the cells of a library for labelling droplets, and we demonstrate the suitability of this method for high-throughput screening of cell growth for both yeasts and bacteria. The potential of this highly generic method is discussed in the context of microbiome functional exploration.

\section{Material \& Methods}

\subsection{Plasmids, strains and mini-library construction}

The pET3-Dendra2 plasmid expressing the Dendra2 (Gurskaya et al., 2006) protein was constructed by cloning of Dendra2 gene coding fragment in Nde1 and BamH1 sites of the pET3-a vector (NOVAGEN) under the control of strong T7 promoter. The BL21 strain, transformed with this plasmid was used in E.coli model experiments.

For mini-library studies, the fluorescent BL21 E.coli strain, carrying the pET3-Dendra2 plasmid was additionally transformed with the fosmids extracted from the metagenomic library clones. Transformants were selected and further grown on LB medium with $100 \mathrm{mg} \cdot \mathrm{L}^{-1}$ ampicillin (Amp) and $12.5 \mathrm{mg} \cdot \mathrm{L}^{-1}$ chloramphenicol $(\mathrm{Cm})$.

Yeast vectors were constructed by insertion of the mEos $2 p$ coding sequence either between the Xba1 and BamH1 restriction sites of the pUG36 (Niedenthal et al., 1996) plasmid (MET25 promoter 
controlled expression), or between the BamH1 and Pst1 restriction sites of the $\mathrm{pCM} 185$ plasmid containing tetO-CYC1 promoter to control expression (Gari et al., 1997). A yeast strain with a deleted TRP1 gene from the YKO collection (MAT alfa hi3 $\Delta 1$ leu2 $\Delta 0$ lys $2 \Delta 0$ ura3 $\Delta 0$ trp1::KANMX) was transformed by the resulting plasmids pUG36-mEos2 and pCM185-mEos2.

\subsection{Hit clone identification by $P C R$}

DNA inserts of clones obtained during metagenomic library screening were identified by PCR amplification using Phusion High fidelity DNA polymerase (NEB) classical protocol. Following pairs of primers were used for amplification of specific regions:

Clone F5 GCGGTCTGCCGATAGCATC and GATGAGTGGCTTGTCCCTG

Clone 53 GAGGTTCGCAGCGGCCAGA and GACGGCGCAAACATGCTGG

Clone 17 CGCACAATACAGAGTCGCG and CGTGCCGGAGGCTGGGG

Clone F4 TGACCATCGAACTGGTCGCC and TCCGGAGACCAAGCAGCC

\subsection{Media and growth conditions}

The $E$. coli strain carrying the $\mathrm{PET} 3-D e n d r a 2$ plasmid was cultivated in LB liquid or solid media with $100 \mathrm{mg} \cdot \mathrm{L}^{-1} \mathrm{Amp}$ at $37^{\circ} \mathrm{C}$.

Yeast strains were grown at $30^{\circ} \mathrm{C}$ in YNB selective medium without uracil or tryptophan for the pUG36-mEos2 and pCM185-mEos2 constructs, respectively.

For mini-library growth and for microfluidics screening minimum synthetic media (M9) with 100 mg. $\mathrm{L}^{-1} \mathrm{Amp}$ and $12.5 \mathrm{mg} \cdot \mathrm{L}^{-1} \mathrm{Cm}$ containing $0.5 \%$ xylo-oligosaccarides (XOS) (Wako chemicals, Japan) as the only carbon source was used. Growth of the mini-library strains was performed as described by (Tauzin et al., 2016) with some modifications. Cells grown in LB medium supplemented with 12.5 mg. $\mathrm{L}^{-1} \mathrm{Cm}$ and $100 \mathrm{mg} \cdot \mathrm{L}^{-1} \mathrm{Amp}$ were inoculated in $\mathrm{M} 9$ with the same antibiotics and $0.5 \%$ of xylose. Overnight cultures from this medium were used to inoculate $0.5 \mathrm{~mL}$ of $\mathrm{M} 9$ XOS medium at $\mathrm{OD}_{600} 0.05$ into 48 -well microplate. The growth was followed by measuring the $\mathrm{OD}_{600}$ over $48 \mathrm{~h}$ at $37^{\circ} \mathrm{C}$ using the FLUOStar Optima (BMG Labtech).

\subsection{Droplet generation with the microfluidic device}

E.coli or S.cerevisiae cell suspensions used for the droplets generation were prepared in corresponding medium just prior the emulsification procedure.

Droplet generation chips and observation chambers were developed and provided by the Colloïdes and Matériaux Divisés Laboratory (LCMD) from the Ecole Supérieure de Physique et Chimie Industrielles of Paris (ESPCI). The water in oil emulsion with the droplets size of approximately $50 \mu \mathrm{M}$ was made by flow-focusing the cell suspension stream with two streams of HFE7500 fluorinated oil (3M) containing 2\% (w/w) 008-FluoroSurfactant (RAN Biotechnologies) (Boitard et al., 2012b). 
For cell growth observation and blue light illumination ("switch") of selected droplets, fluorescent Leica DM4000B microscope and Leica EL6000 light source was used. Pictures were taken using a LEICA DFC300FX camera.

\subsection{Cytometry and sorting}

Analysis of cell populations extracted from the original or "switched" emulsion was performed on a MACS Quant VYB cytometer from Miltenyi Biotec. For red and green fluorescent cells, a 488nm laser with a 500-550nm filter (GREEN state) and 561nm laser with 605-626 filter (RED state) combinations were used. The cell sorting experiments were performed on the MoFlo Astrios EQ cell sorter using the Summit v6.3 software (Beckman Coulter).

Demulsification was performed by adding 100 volumes of TBS buffer, and cells recovered in the aqueous phase were stored at $4^{\circ} \mathrm{C}$ prior to further analysis. Cell sorting was carried out with a $70 \mu \mathrm{m}$ nozzle and 60 psi operating pressure. The sorting speed was kept around 30000 events per second.

To sort cells with the red and green fluorescence state of the Dendra2 (or mEos2) protein simultaneously, the red (560 nm laser, 614/20 filter) and green (488 nm laser, 526/52 filter) level of fluorescence of the strains with non-switched protein was first measured. The level of red fluorescence of the resulting plot was used as a background value. The cells with red fluorescence higher than this background was considered as "switched" cells and sorted.

\section{Results}

In order to develop a workflow for ultra-high throughput screening of cell growth in droplets that is compatible with fluorescent activated cell sorting and living cell recovery, we tested the potential of switchable fluorescent proteins for the labelling of encapsulated growing cells. Two model microorganisms have been chosen for their generic usage in synthetic biology and as screening hosts for protein engineering and activity-based functional metagenomics: the bacteria $E$. coli and the yeast S. cerevisiae. In both cases, cells were rendered fluorescent by plasmid-based expression of PAFPs. These fluorescent strains were used to monitor cell growth and to label selected droplets into a microfluidic chamber.

\subsection{Selective cell labelling, sorting and recovery with two model microorganisms}

\subsubsection{The E. coli DENDRA2p model}

A BL21 E. coli strain expressing the green/red switchable fluorescent protein Dendra2 was used for the proof of concept in bacteria. Green fluorescent cells were re-suspended in LB Amp medium at $\mathrm{OD}_{600 \mathrm{~nm}}$ 0.001 , which corresponds to a theoretical cell concentration of $10^{6}$ cells $/ \mathrm{mL}$. This cell concentration allows emulsion to be formed with around $70 \%$ of empty droplets and $30 \%$ of cell containing droplets. According to Poisson distribution in this case in majority (around 22\%) of populated droplets will be 
found one cell, and two or more cells in the others. After droplet generation, the cell-containing emulsion was incubated in Eppendorf tubes at $37^{\circ} \mathrm{C}$ overnight and observed the next day in a monolayer under the fluorescent microscope. Using the X100 objective, fifteen droplets filled by overnight grown cells were illuminated with blue light $(405 \mathrm{~nm})$ in order to change their fluorescence from the initial green color into red. This magnification allowed precise light targeting of a selected droplet without switching the fluorescence of neighboring droplets. Figure 1 shows the result of illumination of one of the green droplets that led to the appearance of red fluorescence due to conformational changes of the Dendra2p molecules in the encapsulated E. coli cells (Fig 1A). After the "switch", all the droplets from the observation chamber were collected, immediately broken and released cells were kept in TBS buffer. The buffer, and not a culture medium, was used in order to keep cells alive, but not growing and not synthetizing de novo Dendra2 protein. The cell suspension was then analyzed by the cytometer and the appearance of a new, red fluorescent cell population was detected (Fig 1B). Subsequently, the green and red populations were separated using FACS. In order to check the effect of the illumination and fluorescence switch on viability, the survival of these two sorted populations was compared: 4000 red and 4000 green FACS sorted cells were plated on LB+Amp medium and grown at $37^{\circ} \mathrm{C}$. After 2 days of incubation 1,127 (28\% from sorted ones) red cells formed colonies. Survival of green (non-switched) cells after the sorting procedure was $43 \%$, meaning that our "switching" parameters were slightly harmful for the cells, but did not dramatically reduce their survival after sorting. Considering that several living cells were recovered from one single droplet after overnight cell growth, we presume that even with a survival rate of $28 \%$, the whole "switch+FACS" procedure applied to $E$. coli should allow us to recover enough cells from each labelled droplet during the screening procedure.

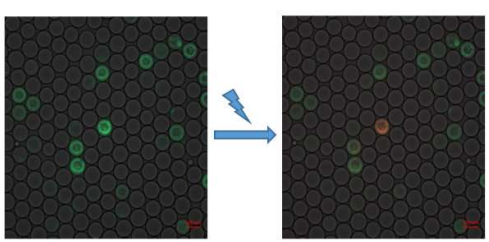

A.

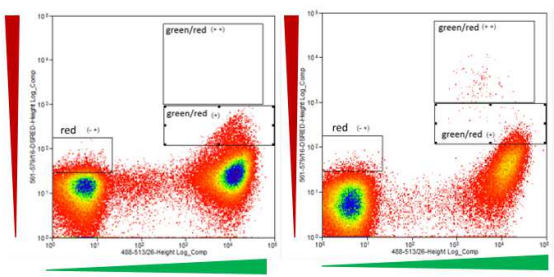

B.
Figure 1A. Switching of Dendra2p fluorescence in E.coli cells grown in droplets green/red overlay images. E.coli BL21 strain expressing Dendra2 fluorescent protein were grown during 24 hours at $37^{\circ} \mathrm{C}$ in LB+Amp medium. Selected droplets were zoomed with $100 \mathrm{X}$ objective and illuminated during $30 \mathrm{sec}$ by blue light using EL6000 light source and 435/40 Bright Line HC filter. Images were taken with $20 \mathrm{X}$ objective before ( $1 \mathrm{~A}$ left) and after (1 $\mathrm{A}$ right) illumination. the "switch" of Dendra2 protein. X axes correspond to the green fluorescence level, $Y$ - to the red. Cells recovered from the emulsion illuminated (right) or not (left) with the blue light in observation chamber were analyzed and sorted by FACS. New red fluorescent cells population appearing in the upper right corner of the plot is the result of fluorescence switch of Dendra2 protein in few selected droplets of the chamber.

\subsubsection{The $S$. cerevisiae mEos $2 p$ model}

S. cerevisiae strains expressing the mEos2 fluorescent protein were used to demonstrate usefulness of this strategy for yeast. In addition, to address the question whether fluorescence intensity influences the performance and accuracy of the selective systems, in this model the mEos 2 gene was placed 
under the control of two different promoters: a strong tetO-CYC1 promoter and a weaker - MET25 promoter. Cells transformed by these plasmids exhibited different levels of fluorescence (Fig 2). Similarly to the $E$. coli experiment, 1 cell-per-droplet emulsions were prepared from these different strains, by using cell suspension at $\mathrm{OD}_{600 \mathrm{~nm}} 0.05$ (which corresponds to a theoretical cell concentration of $5.0 \times 10^{5}$ cells $/ \mathrm{mL}$ ). Twenty droplets from each emulsion were "switched" by blue light illumination (Fig 2A) and the cells recovered from the observation chambers with and without a switch were compared. Cytometry plots (Fig 2B) show for both strains expressing mEos2 gene at different level, the appearance of a new red cell population after the blue light illumination, clearly distinguishable from the background. Fluorescence based sorting of these switched cells was as successful as in the case of $E$. coli, although the intensity of fluorescence of both yeast strains was much lower than that of Dendra2p expressing bacteria. Testing for viability following the sorting of red and green cells showed, as in the case of $E$. coli, that blue light treatment slightly influences the survival of yeast cells recovered after FACS : $22 \%$ of treated vs $34 \%$ of non-treated cells formed colonies on YNB plates.

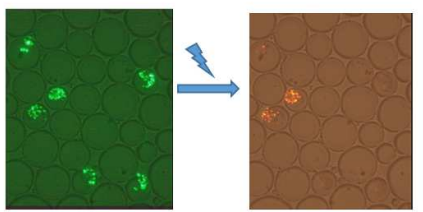

A.
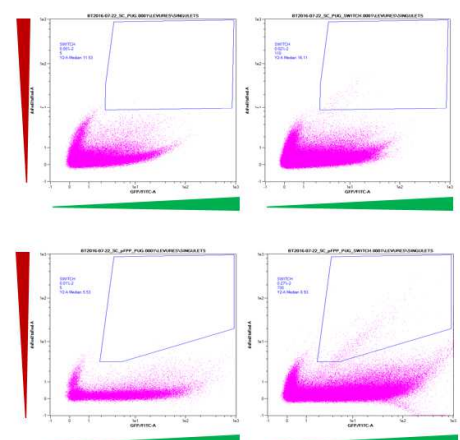

B.
Figure 2A. Switching of mEos2 fluorescence in S.cerevisiae. Result of fluorescent switch of two droplets containing yeast cells grown in YNB medium. Images are taken in green (left) or in red (right) channels before and after the switch.

Figure 2B. Cytometry plots before and after "switch" of mEos2 protein in S.cerevisiae. mEos2 protein expressed from the plasmid at different level in two yeast strains - lower expression from MET25 promoter (upper plots), higher - from tet0-CYC1(lower plots). After the "switch" (two right plots) for both strains increased amount of "red" cells is detected by cytometer, allowing further sorting by fluorescence.

\subsection{Application to functional metagenomic}

In order to exemplify the use of our fluorescence switching based screening for functional metagenomic, we analyzed the growth phenotype of a synthetic mini-library issued from the human ileal and fecal microbiomes. Four E. coli clones selected as positives by conventional screening of metagenomic libraries for prebiotic metabolization pathways (Cecchini et al., 2013) were used to construct this mini-library (F3, F4, F5 and 17). These clones all contain 30-40 kb metagenomic DNA fragments cloned in fosmid pCC1FOS, which encode at least one glycoside-hydrolase (GH) acting on xylo-oligosaccarides (XOS). These GHs are produced intracellularly in E. coli. In conventional screening, they are released during the spontaneous cell lysis occurring when the clones are cultured during 1 to 3 weeks on solid medium containing XOS as sole carbon source (Cecchini et al., 2013). This allows the enzymes to access the extracellular substrate, and to degrade it into xylose that will boost cell growth and result in the apparition of colonies. In addition, the metagenomic sequence of clones F3, F5 and 17 also encode XOS transporters that could, with the appropriate intracellular GHs, confer to $E$. coli the ability to both internalize and to fully hydrolyze XOS into xylose, as demonstrated for F5 (Tauzin et al., 2016). In contrast F4 does not contain any oligosaccharide transporter sequence (Cecchini et al., 2013). 
Here, we extracted fosmids from these clones and used them separately to transform the BL21 E. coli strain expressing the DENDRA2 fluorescent protein.

The resulting fluorescent clones were checked in liquid cultures for the ability to grow on XOS-selective medium in order to assess the influence of Dendra2 expression on that of the metagenomic genes. The growth of all the positive clones issued from the conventional screening on solid medium was confirmed in liquid cultures, except for the clone F4 that does not contain any oligosaccharide transporter sequence (Fig. 3).

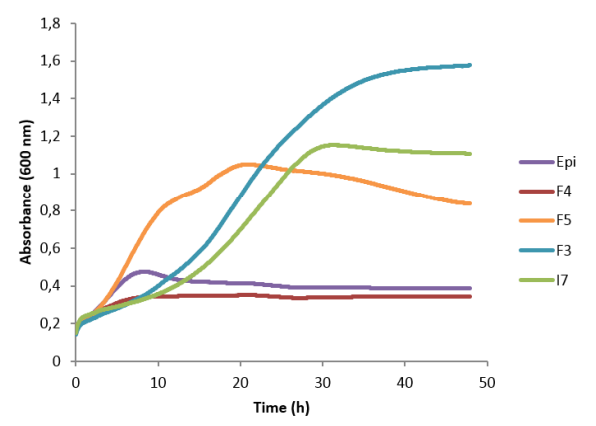

224 the droplet fluorescence.

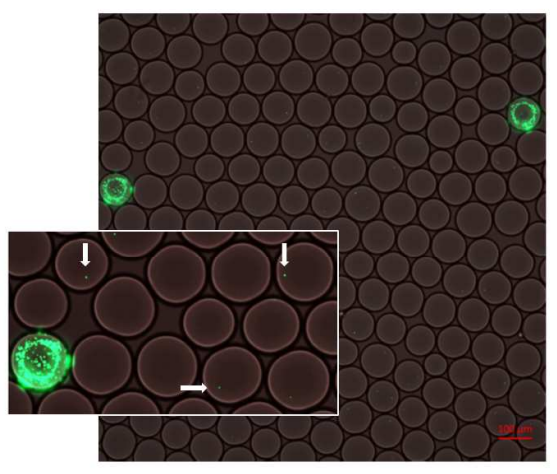

Figure 3. Growth curves in liquid XOS-selective medium of the fluorescent BL21 pET3-Dendra2 strains carrying metagenomic fosmids. The $\lceil 5, \Gamma 3$, and 17 metagenomic sequences confer XOS utilization to E. coli, through the expression of functional XOS transporters and hydrolytic enzymes, although growth rate differs depending on the metagenomic sequence. Clone with empty fosmid (Epi) and negative clone F4, which only expresses XOS hydrolytic enzymes, didn't grow.

Then, the growth of each of these fluorescent clones on XOS-selective medium was separately checked in droplets. As expected, both the Epi negative control containing the empty fosmid and the F4 clone didn't grow in droplets. Clones F3, F5 and 17 correctly divided, which resulted in a dramatic increase of

The final step of the proof of concept consisted in mixing XOS metabolizing and not-metabolizing clones and to use the resulting mini-library for screening in our microfluidic system. Clones F3, F4, F5 and 17 were added at an equal ratio in a mixture and the negative one (Epi) at 1000 times excess to get the ratio close to a real metagenomic library (Cecchini et al., 2013; Tasse et al., 2010). This cell suspension in XOS-selective medium at an $\mathrm{OD}_{600 \mathrm{~nm}}$ of 0.05 was used for encapsulation. The resulting library emulsion was incubated in Eppendorf tubes at $37^{\circ} \mathrm{C}$ during $24 \mathrm{~h}$. We observed few very fluorescent droplets with good growth, which presumably contained positive clones (Fig 4).

Figure 4. Mini-library growth in droplets on XOS-selective medium. Mini-library E.coli cells at $\mathrm{OD}_{600 \mathrm{~nm}} \mathrm{O}, 05$ in XOS M9 medium was encapsulated for the screening. After $24 \mathrm{~h}$ of incubation highly fluorescent droplets corresponding to positive hits, surrounded by many droplets with 1-3 non-grown fluorescent cells (white arrows) are observed.

The majority of droplets had one to three small fluorescent spots corresponding to the single initial fluorescent cell encapsulated in the droplet, which was unable to grow on this substrate. Fifteen highly fluorescent droplets were "switched" and 1112 red cells from recovered and broken emulsion were 
collected by sorting with FACS. All the sorted red cells were plated on solid $\mathrm{LB}+\mathrm{Cm}$ medium, and resulted in around 300 colonies after 24 hours of incubation. We randomly selected 20 colonies for growth validation in liquid XOS-selective medium. All the cells were able to grow, meaning that labelling and sorting allowed to perfectly select the clones that are able to grow in selective conditions. The identity of these 20 positive clones was then checked by PCR using pairs of primers specific to each metagenomic DNA insert. Clones F5, 17 and F3 were present in almost equal amount (9:6:5). No F4 was found confirming that this insertion is not able to confer growth on this substrate in liquid medium.

247

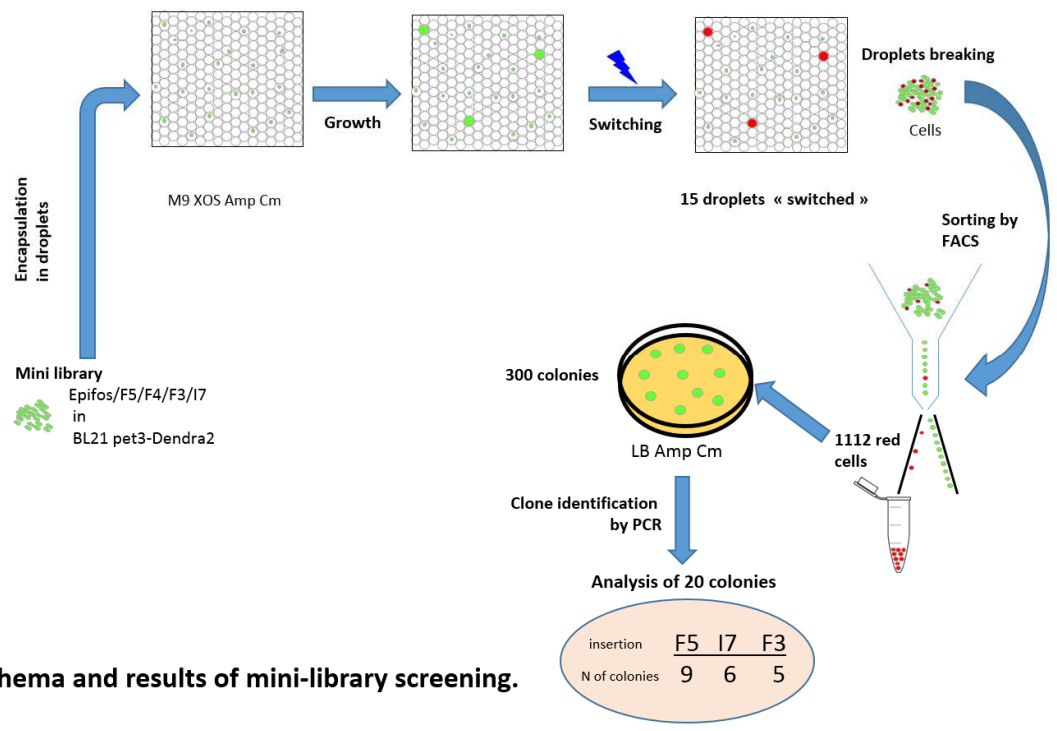

This whole experiment presented in figure 5, demonstrate that the cells representing each positive clone from the library were recovered after random switching growing droplets, and following cell sorting. No F4 was found, confirming that contrary to conventional screening on solid plates, our method allowed us to discriminate the clones that code or not for a complete XOS metabolization pathway involving an active transport system.

\section{Discussion}

In this paper we present a new droplet-microfluidic workflow to screen microbial libraries for growth phenotypes. Original way of labelling used in this method includes fluorescence color switching in the droplets and sorting of "switched" selected cells, steps which can be easily done using readily available laboratory tools: a fluorescent microscope and a FACS machine. We chose E.coli and S.cerevisiae strains expressing switchable fluorescent proteins as model examples of commonly used microorganisms, and showed that in both systems our method gives reliable results. The estimation of cell viability for both microorganisms after sorting showed slightly harmful effect of blue light treatment during the "switch". However, lethality level due to this effect should not significantly influence the yield of microfluidic or millifluidic screenings, since each droplet normally contains big number of switched cells (100-1000), and 30\% of survival is enough for further analysis. If in some cases lethality becomes critical for the screening, modulation of exposure to blue light source by the time, strength and wavelength ( 488 instead of $405 \mathrm{~nm}$ ) of the illumination might be considered. 
In order to confirm the relevance of this new method for metagenomic library screening, we used an artificially created mini-library consisting of previously characterized positive metagenomic clones issued from conventional screening on solid medium (Cecchini et al., 2013; Tauzin et al., 2016) . With this model we demonstrated that after the complete procedure, all the positive clones metabolizing a specific substrate are successfully recovered. In addition, in our screening we were able to perfectly discriminate clones that are really able to grow in a selective medium (clones P5, F3 and 17) from those, like clone F4, which only produce enzymes to hydrolyze the substrate but no transporter to internalize it. This type of clones, in fact, constitute false positives picked from solid media, on which only substrate degradation can be specifically screened. This selectivity is an important advantage of microfluidics compared to conventional high-throughput screening on solid media which is actually the most extensively used method for the functional exploration of microbial libraries issued from protein engineering and metagenomic studies (Ufarté et al., 2015). But the most striking interest of our workflow, as well as of any micro- or millifluidic screen, is the significant reduction of the required substrate amount, compared to positive selection in liquid media performed by a classical way in micro-plates. Here, for the generation of more than 10000 droplets we used only $200 \mu \mathrm{L}$ of selective substrate containing medium, whereas the volume required to screen 1000 individual clones in the micro-plates would be $250 \mathrm{~mL}$. Even though, for the moment, switching is done manually for each droplet, it is easily possible to screen in a few minutes a library of several thousands of cells. One chamber is indeed enough to observe around 10000 droplets and each droplet "switch" takes couple of minutes. Furthermore, libraries screened for positive growth can be encapsulated with higher density (more than 1 cell per droplet), allowing to increase positive hits proportion and decrease screening time.

Another interesting application of our method related to implication of microscopy observation step, could be phenotypes targeting that cannot be easily screened on solid medium. For example variation of cell form due to genomic mutations, changed colony development, such as hyphal or pseudo hyphal growth, induced for some microorganisms by specific conditions. For this type of screenings fluorescent switchable protein serves as a cell labelling switchable marker and also facilitate visualization of the growth in droplets. However, we can conceive than for screening other features PSFP may have an additional function: it can be used for expression monitoring if placed under the investigated promoter or can help for following the protein localization if expressed in fusion with the protein of interest. In those cases, droplets where changed expression or localization phenotype is observed, can be later switched and sorted, using the same method as in the examples shown in this work. We believe that the labelling tool described in this study will enlarge the applications of microfluidic systems in molecular biology, protein engineering and functional metagenomics.

\section{Acknowledgements}

This research was funded by ANR (DYNAMETAFLUID N ${ }^{\circ}$ ANR-14-CE08-0008-02), and by the European Union's framework programme Horizon 2020 (LEIT-BIO-2015-685474, Metafluidics and MSCA-IF2015_707457, Catsys).

\section{References}

Agresti, J.J., Antipov, E., Abate, A.R., Ahn, K., Rowat, A.C., Baret, J.-C., Marquez, M., Klibanov, A.M., Griffiths, A.D., Weitz, D.A., 2010. Ultrahigh-throughput screening in drop-based microfluidics for directed evolution. Proc. Natl. Acad. Sci. 107, 4004-4009. 
Baret, J.-C., Miller, O.J., Taly, V., Ryckelynck, M., El-Harrak, A., Frenz, L., Rick, C., Samuels, M.L., Hutchison, J.B., Agresti, J.J., Link, D.R., Weitz, D.A., Griffiths, A.D., 2009. Fluorescence-activated droplet sorting (FADS): efficient microfluidic cell sorting based on enzymatic activity. Lab Chip 9, 1850-1858.

Boitard, L., Cottinet, D., Kleinschmitt, C., Bremond, N., Baudry, J., Yvert, G., Bibette, J., $2012 a$. Monitoring single-cell bioenergetics via the coarsening of emulsion droplets. Proc. Natl. Acad. Sci. 109, 7181-7186.

Boitard, L., Cottinet, D., Kleinschmitt, C., Bremond, N., Baudry, J., Yvert, G., Bibette, J., 2012 b. Monitoring single-cell bioenergetics via the coarsening of emulsion droplets. Proc. Natl. Acad. Sci. 109, 7181-7186.

Cecchini, D.A., Laville, E., Laguerre, S., Robe, P., Leclerc, M., Doré, J., Henrissat, B., Remaud-Siméon, M., Monsan, P., Potocki-Véronèse, G., 2013. Functional Metagenomics Reveals Novel Pathways of Prebiotic Breakdown by Human Gut Bacteria. PLoS ONE 8, e72766.

Chudakov, D.M., Lukyanov, S., Lukyanov, K.A., 2007. Tracking intracellular protein movements using photoswitchable fluorescent proteins PS-CFP2 and Dendra2. Nat Protoc. 2, 2024-2032.

Colin, P.-Y., Kintses, B., Gielen, F., Miton, C.M., Fischer, G., Mohamed, M.F., Hyvönen, M., Morgavi, D.P., Janssen, D.B., Hollfelder, F., 2015. Ultrahigh-throughput discovery of promiscuous enzymes by picodroplet functional metagenomics. Nat. Commun. 6, 10008.

Garí, E., Piedrafita, L., Aldea, M. and Herrero, E., 1997. A Set of Vectors with a Tetracycline-Regulatable Promoter System for Modulated Gene Expression in Saccharomyces cerevisiae. Yeast. 13: 837848.

Gielen, F., Colin, P.-Y., Mair, P., Hollfelder, F., 2018. Ultrahigh-Throughput Screening of Single-Cell Lysates for Directed Evolution and Functional Metagenomics, in: Bornscheuer, U.T., Höhne, M. (Eds.), Protein Engineering: Methods and Protocols. Springer New York, New York, NY, pp. 297-309.

Gielen, F., Hours, R., Emond, S., Fischlechner, M., Schell, U., Hollfelder, F., 2016. Ultrahigh-throughputdirected enzyme evolution by absorbance-activated droplet sorting (AADS). Proc. Natl. Acad. Sci. 113, E7383-E7389.

Gurskaya, N.G., Verkhusha, V.V., Shcheglov, A.S., Staroverov, D.B., Chepurnykh, T.V., Fradkov, A.F., Lukyanov, S., Lukyanov, K.A., 2006. Engineering of a monomeric green-to-red photoactivatable fluorescent protein induced by blue light. Nat Biotech 24, 461-465.

Hosokawa, M., Hoshino, Y., Nishikawa, Y., Hirose, T., Yoon, D.H., Mori, T., Sekiguchi, T., Shoji, S., Takeyama, H., 2015. Droplet-based microfluidics for high-throughput screening of a metagenomic library for isolation of microbial enzymes. Spec. Issue Biosens. 2014 67, 379385.

Lukyanov, K.A., Chudakov, D.M., Lukyanov, S., Verkhusha, V.V., 2005. Innovation: photoactivatable fluorescent proteins. Nat Rev Mol Cell Biol 6, 885-891.

Mazutis, L., Gilbert, J., Ung, W.L., Weitz, D.A., Griffiths, A.D., Heyman, J.A., 2013a. Single-cell analysis and sorting using droplet-based microfluidics. Nat. Protoc. 8, 870-891.

Mazutis, L., Gilbert, J., Ung, W.L., Weitz, D.A., Griffiths, A.D., Heyman, J.A., 2013b. Single-cell analysis and sorting using droplet-based microfluidics. Nat. Protoc. 8, 870-891.

Miyawaki, A., Nagai, T., Mizuno, H., 2003. Mechanisms of protein fluorophore formation and engineering. Curr. Opin. Chem. Biol. 7, 557-562.

Molina, A.J.A., Shirihai, O.S., 2009. Chapter 16 Monitoring Mitochondrial Dynamics with Photoactivateable Green Fluorescent Protein, in: Methods in Enzymology. Academic Press, pp. 289-304.

Niedenthal RK., Riles L., Johnston M., Hegemann JH., 1996. Green fluorescent protein as a marker for gene expression and subcellular localization in budding yeast. Yeast. 30:773-86

Najah, M., Calbrix, R., Mahendra-Wijaya, I.P., Beneyton, T., Griffiths, A.D., Drevelle, A., 2014. DropletBased Microfluidics Platform for Ultra-High-Throughput Bioprospecting of Cellulolytic Microorganisms. Chem. Biol. 21, 1722-1732. 
Sjostrom, S.L., Bai, Y., Huang, M., Liu, Z., Nielsen, J., Jönsson, H., Svahn, H.A., 2014. High-throughput screening for industrial enzyme production hosts by droplet microfluidics. Lab. Chip 14, 806813.

Tasse, L., Bercovici, J., Pizzut-Serin, S., Robe, P., Tap, J., Klopp, C., Cantarel, BL., Coutinho, PM., Henrissat, B., Leclerc, M., Doré, J., Monsan, P., Remaud-Simeon,M., Potocki-Veronese, G.,2010. Functional metagenomics to mine the human gut microbiome for dietary fiber catabolic enzymes. Genome res. 11, 1605-1612.

Tauzin, A.S., Laville, E., Xiao, Y., Nouaille, S., Le Bourgeois, P., Heux, S., Portais, J.-C., Monsan, P., Martens, E.C., Potocki-Veronese, G., Bordes, F., 2016. Functional characterization of a gene locus from an uncultured gut Bacteroides conferring xylo-oligosaccharides utilization to Escherichia coli. Mol. Microbiol. 102, 579-592.

Terekhov, S.S., Smirnov, I.V., Stepanova, A.V., Bobik, T.V., Mokrushina, Y.A., Ponomarenko, N.A., Belogurov, A.A., Rubtsova, M.P., Kartseva, O.V., Gomzikova, M.O., Moskovtsev, A.A., Bukatin, A.S., Dubina, M.V., Kostryukova, E.S., Babenko, V.V., Vakhitova, M.T., Manolov, A.I., Malakhova, M.V., Kornienko, M.A., Tyakht, A.V., Vanyushkina, A.A., Ilina, E.N., Masson, P., Gabibov, A.G., Altman, S., 2017. Microfluidic droplet platform for ultrahigh-throughput singlecell screening of biodiversity. Proc. Natl. Acad. Sci. U. S. A. 114, 2550-2555.

Ufarté, L., Potocki-Veronese, G., Laville, É., 2015. Discovery of new protein families and functions: new challenges in functional metagenomics for biotechnologies and microbial ecology. Front. Microbiol. 6, 563.

Wang, B.L., Ghaderi, A., Zhou, H., Agresti, J., Weitz, D.A., Fink, G.R., Stephanopoulos, G., 2014. Microfluidic high-throughput culturing of single cells for selection based on extracellular metabolite production or consumption. Nat Biotech 32, 473-478.

Zhang, L., 2007. Method for real-time monitoring of protein degradation at the single cell level. Biotechniques 42.

Zinchenko, A., Devenish, S.R.A., Kintses, B., Colin, P.-Y., Fischlechner, M., Hollfelder, F., 2014. One in a Million: Flow Cytometric Sorting of Single Cell-Lysate Assays in Monodisperse Picolitre Double Emulsion Droplets for Directed Evolution. Anal. Chem. 86, 2526-2533.

\section{Figure legends}

Figure 1A. Switching of Dendra2p fluorescence in E.coli cells grown in droplets green/red overlay images. E.coli BL21 strain expressing Dendra2 fluorescent protein were grown during 24 hours at $37^{\circ} \mathrm{C}$ in LB+Amp medium. Selected droplets were zoomed with 100X objective and illuminated during $30 \mathrm{sec}$ by blue light using EL6000 light source and 435/40 Bright Line HC filter. Images were taken with 20X objective before ( $1 \mathrm{~A}$ left) and after (1A right) illumination.

Figure 1B. FACS images of cells populations before and after the "switch" of Dendra2 protein. X axes correspond to the green fluorescence level, $Y-$ to the red. Cells recovered from the emulsion illuminated (right) or not (left) with the blue light in observation chamber were analyzed and sorted by FACS. New red fluorescent cells population appearing in the upper right corner of the plot is the result of fluorescence switch of Dendra2 protein in few selected droplets of the chamber.

Figure 2A. Switching of mEos2 fluorescence in S.cerevisiae. Result of fluorescent switch of two droplets containing yeast cells grown in YNB medium. Images are taken in green (left) or in red (right) channels before and after the switch. 
Figure 2B. Cytometry plots before and after "switch" of mEos2 protein in S.cerevisiae. mEos2 protein expressed from the plasmid at different level in two yeast strains - lower expression from MET25 promoter (upper plots), higher - from tet0-CYC1(lower plots). After the "switch" (two right plots) for both strains increased amount of "red" cells is detected by cytometer, allowing further sorting by

411 fluorescence.

Figure 3. Growth curves in liquid XOS-selective medium of the fluorescent BL21 pET3-Dendra2 strains carrying metagenomic fosmids. The F5, F3, and 17 metagenomic sequences confer XOS utilization to E. coli, through the expression of functional XOS transporters and hydrolytic enzymes, although growth rate differs depending on the metagenomic sequence. Clone with empty fosmid (Epi) and negative clone F4, which only expresses XOS hydrolytic enzymes, didn't grow.

418 Figure 4. Mini-library growth in droplets on XOS-selective medium. Mini-library E.coli cells at $\mathrm{OD}_{600 \mathrm{~nm}}$ 4190,05 in XOS M9 medium was encapsulated for the screening. After $24 \mathrm{~h}$ of incubation highly fluorescent 420 droplets corresponding to positive hits, surrounded by many droplets with 1-3 non-grown fluorescent 421 cells (white arrows) are observed. Figure 5. Schema and results of mini-library screening. 